\title{
The acquisition of obesity: insights from cellular and genetic research
}

\author{
Martin Wabitsch \\ Department of Pediatrics, University of Ulm, Prittwitzstr. 43, 89075 Ulm, Germany
}

\begin{abstract}
The acquisition of increased adipose tissue mass in man occurs during prolonged periods of positive energy balance. Normally, energy homeostasis in children and adults is regulated strictly and the energy stores are kept within the defined age-dependent physiological range. Susceptibility to definitive increases in the level of energy balance during times of reduced energy consumption or increased energy intake, leading to changes in body composition and/or changes in relative body weight, seems to be genetically determined. Although at present much information on the regulation of energy homeostasis and related unfavourable factors exists from animal studies, knowledge of the regulation of energy balance in human subjects is still insufficient. Some evidence on relevant factors involved in the regulation of energy balance in man has been obtained from epidemiological data, as well as from studies of patients with rare monogenetic forms of obesity. In the present article a special focus will be put on the regulation of body energy stores at the level of the adipose tissue, with emphasis on the regulation of human adipocyte differentiation. In addition to the currently intensive scientific interest in the central regulation of energy homeostasis in man, there is sufficient evidence to support the idea that the acquisition of an increased adipose tissue mass is also dependent on the susceptibility of pre-adipocytes to proliferate, to differentiate or to enter into apoptosis.
\end{abstract}

Obesity: Childhood: Adipose tissue

\section{General considerations about the regulation of the body's energy stores}

During adult life the energy content of the body remains generally stable over time, with only minor long-term changes. Rosenbaum \& Leibel (1998) recently summarized current knowledge about the regulation of the body's energy balance. From the point of view of energy, the mass of the human body can be divided into two different compartments: the lean or fat-free body mass in which energy is stored as carbohydrates and proteins; body fat mass in which energy is stored as triacylglycerols. The most important organ for the storage of triacylglycerols is the adipose tissue, in which adipocytes have a mean triacylglycerol content of $1 \mu \mathrm{g}$ or $17 \mathrm{~mJ}$. Changes in the relative and absolute amounts of lean and/or fat body mass will result in changes in the body's energy content which can, but does not necessarily, also result in changes in body weight.

During growth and development in childhood, body weight and body composition follow physiological changes (Dugdale, 1975). The growth curve of adipose tissue during childhood has two maxima: one at birth; the other before the onset of puberty when the increase in fat mass is highest.
The latter seems to be an important trigger for pubertal development. The marked changes in body composition and body growth during childhood until adulthood occur in as strict a physiological framework as does the control of body weight and body composition.

Changes in body energy content reflect the balance between energy intake and energy expenditure. Energy intake is possible normally only by the consumption of food which is partly regulated by hunger and satiety. Energy expenditure comprises mainly the energy expended for $\mathrm{BMR}$, the energy needed for physical exercise, and in children the energy required for growth.

The observation that voluntarily-induced weight loss might be easy to achieve, but that a reduced body weight is very difficult to maintain, demonstrates in addition the presence of a regulatory system controlling body energy content which is genetically determined. Similarly, final height, body weight and body composition are influenced by genetic factors, which in a child can be estimated from the respective data for the parents. Studies on twins and adoptees have provided evidence that there is a strong genetic influence on the development of body weight and 
body composition (for summary, see Rosenbaum \& Leibel, 1998).

However, longitudinal studies and epidemiological data have shown that changes in the conditions of daily life also result in changes in body weight and body composition. Unlike final height, considerable changes in body weight can be induced by the environment. The increasing prevalence of obesity, especially in children and adolescents, in recent years seems to be mainly attributable to a marked decrease in physical activity and to a unfavourable change in food consumption patterns in surroundings which provide a rich choice of energy-dense and high-fat foods.

Interestingly, there is evidence from epidemiological data (Troiano \& Flegal, 1998) that there is considerable variation in the susceptibility to weight gain in response to environmental changes. A recent study in human subjects revealed an unknown specific mechanism responsible for the differing susceptibility to weight gain during overeating in an experimental setting (Levine et al. 1999). It is suggested that susceptibility to weight gain, and in the same way susceptibility to weight loss, under changing environmental conditions is likely to be determined genetically, unlike body energy content and body weight per se.

The energy content of the human body is under the control of several regulatory systems (e.g. systems regulating hunger and satiety, body temperature, sympathetic nervous system and several others), the signals of which are integrated in the hypothalamus. Obesity results from changes in these regulatory systems, when a lack of adequate counter regulation occurs and a positive energy balance is present for a longer time period. Recent scientific data have clearly refuted the once widespread theory that obesity in an individual just reflects a lack of willpower (Rosenbaum \& Leibel, 1998).

In addition to these considerations regarding the situation in the human subject, there is a considerable body of evidence from animal studies that body weight is regulated by genetic factors and that the main regulating centres are in the brain (Rosenbaum \& Leibel, 1998).

Interestingly, recent investigations of the regulation of the energy balance in rodents and human subjects have revealed not only the complex system involved in stabilizing energy balance, but have also shown that the amount of energy stored in adipose tissue is related to various biological functions, including the regulation of growth, puberty, reproduction and the immune system (Friedman \& Halaas, 1998).

In principle, all the regulatory systems involved in the control of energy balance contain several crucial steps where candidate genes which might be important for body weight regulation can be found. An updated overview of some of the systems involved in body-weight regulation has been published recently (Rosenbaum \& Leibel, 1998).

In the following section findings in patients with rare monogenetic forms of obesity are summarized, in order to provide some insights into these complex regulatory systems and to learn about the consequences of a defect in a single gene. It should be emphasized that the information obtained from these patients currently represents the only data providing conclusive evidence of the effects of these factors in man. Although there have been a number of findings from animal studies elucidating the role of signalling factors in the control of body weight, it has to be remembered that most of those findings vary between species and cannot be directly extrapolated to the situation in human subjects.

\section{Lesions from monogenetic forms of obesity in man}

At present, to our knowledge, six monogenetic forms of human obesity have been identified. All of them have only recently been described and are very rare endocrine disorders that result in early-onset obesity and a variety of associated symptoms, as outlined in the following section.

\section{Congenital leptin deficiency}

Montague et al. (1997) were the first to describe two patients with congenital leptin deficiency. Further individuals with leptin deficiency in a Turkish family have also been described (Strobel et al. 1998). The two children described by Montague et al. (1997) are cousins within a highly consanguinous family of Pakistani origin. The children had a normal birth weight but developed severe obesity within the first months of life. Patient 1 weighed $86 \mathrm{~kg}$ at the age of 8 years and patient 2 weighed $29 \mathrm{~kg}$ at the age of 2 years. Both children were of normal height when leptin deficiency was diagnosed. The patients were characterized by hyperphagia due to impaired satiety. The genetic defect consisted of a deletion of a single guanine nucleotide of the leptin gene. The patients are currently being treated with recombinant human leptin and are losing significant weight and adipose tissue mass. These patients have provided the first evidence that leptin is an important regulator of energy balance in man.

\section{Leptin receptor defect}

Clement et al. (1998) described patients in one family with a mutation in the human leptin receptor gene which was associated with obesity and pituitary dysfunction. The mutation resulted in a truncated leptin receptor lacking both the transmembrane and the intracellular domains. The patients were characterized by early-onset morbid obesity, although they had a normal birth weight. By contrast with the two children with leptin deficiency, the sisters affected by a leptin receptor defect were detected after the pubertal period and showed no pubertal development, with a lack of detectable mammary glands, sparse pubic hair, no axillar hair and amenorrhoea due to hypogonatotropic hypogonadism. It is interesting to see that although they were obese, these patients had no advanced bone age or increased growth rate. However, they showed mild growth delay during early childhood associated with decreased serum concentrations of insulin-like growth factor (IGF)-I and IGF-binding protein-3. In addition, it is possible that the patients could have had hypothalamic hypothyroidism. Like the patients with leptin deficiency, they exhibited hyperphagia and an abnormal eating behaviour. These clinical descriptions of the affected patients indicate that a functional leptin receptor is required not only for the 
regulation of body weight, but also for sexual maturation and for the secretion of growth- and thyrotropic hormones. Leptin is, therefore, a potential critical link between energy stores and hypothalamic pituitary functions in man.

\section{Prohormone convertase I defect}

Jackson et al. (1997) have described a woman who is heterozygous for mutations in the prohormone convertase 1 (PC 1) gene. Before detecting the genetic defect, the patient had already been described as having extreme childhoodonset obesity. Special features in this patient were an abnormal glucose homeostasis despite low insulin levels, and postprandial hypoglycaemia; both features being related to increased serum concentrations of proinsulin. In addition, the patient was characterized by hypogonadotropic hypogonadism and hypocortisolism. These findings may be explained by the function of PC 1 which is suggested to be defective in this patient. PC 1 acts proximately to carboxypeptidase $\mathrm{E}$, the enzyme mutated in the fat/fat mouse. PC 1 is active in the post-translational processing and sorting of prohormones and neuropeptides. Products of PC 1 (and carboxypeptidase E) action have been implicated in the neuroendocrine control of energy balance, and include $\alpha$-melanocyte-stimulating hormone ( $\alpha$-MSH) and glucagonlike peptide-1 derived from pro-opiomelanocortin (POMC) and proglucagon respectively.

\section{Pro-opiomelanocortin deficiency}

Krude et al. (1998) studied two patients with severe earlyonset obesity, adrenal insufficiency and red hair pigmentation. Stimulated by the results of studies in animal models, especially in the yellow obese mouse, which elucidated a central role for $\alpha-\mathrm{MSH}$ in the regulation of food intake, this group was prompted to search for mutations within the POMC gene of these patients. In patient 1 they found two mutations interfering with synthesis of adrenocorticotropic hormone and $\alpha-\mathrm{MSH}$. In patient 2 they found a mutation which abolishes POMC translation. These two patients provide evidence that defects in POMC synthesis can result in early-onset obesity and further endocrine disorders resulting from the defect in this precursor protein which normally generates the melanocortin peptides, adrenocorticotropic hormone and $\alpha-, \beta$ - and $\gamma$-MSH, as well as the opioid-receptor ligand $\beta$-endorphin. Since $\alpha$-MSH is a ligand for the melanocortin-4-receptor, which when activated is able to lead to a decrease in food intake (satiety), it is evident that the hyperphagia observed in patients with POMC deficiency is at least partly due to the lack of $\alpha$-MSH, which thus seems to be essential for body-weight regulation.

\section{Melanocortin-4 receptor defect}

Recently, two reports have been published on a frameshift mutation in human melanocortin-4 receptor associated with a dominant form of obesity (Vaisse et al. 1998; Yeo et al. 1998). A defect in the melanocortin-4 receptor function leads to a lack of satiety and uncontrolled overeating. From animal studies it was already known that a dysfunction in the $\alpha$-MSH-melanocortin-4 receptor system can cause obesity due to hyperphagia.

Defect in the peroxisome-proliferator-activated receptor $\gamma-2$

In a group of 121 obese subjects Ristow et al. (1998) identified four patients with a missense mutation in the gene for peroxisome-proliferator-activated receptor (PPAR) $\gamma$-2. They showed that over-expression of the mutant gene in preadipocytes was associated with accelerated differentiation. The authors suggested that the mutated gene in these subjects could be the cause of increased adipocyte differentiation in their adipose tissue. If so, this would be the only monogenetic form of human obesity described to date in which the genetic defect is not associated with central regulation of energy homeostasis. However, these findings, especially the demonstrated high prevalence of this mutation, need to be confirmed in other cohorts of obese patients.

The major characteristics of the monogenetic forms of obesity in man are summarized in Table 1.

\section{Regulation of human adipose tissue growth and development}

A lot of scientific work has focused in the last two decades on the study of adipose tissue growth and development in human subjects (Ailhaud \& Hauner, 1997). Since the regulation of energy stores in the human body is a crucial part of the complex regulatory system of energy balance, and since in the author's laboratory much effort has been put into elucidating the regulation of adipose tissue growth, differentiation and metabolism, this section will focus on molecular and biological factors involved in the function of adipose tissue as the main energy store in man.

Table 1. Monogenetic causes of non-syndromal obesity in man

\begin{tabular}{|c|c|c|c|c|}
\hline \multicolumn{2}{|c|}{ Mutations Inheritance } & $\begin{array}{l}\text { Time of } \\
\text { onset of } \\
\text { obesity }\end{array}$ & $\begin{array}{l}\text { Pubertal } \\
\text { development }\end{array}$ & $\begin{array}{l}\text { Other specific } \\
\text { features }\end{array}$ \\
\hline$a b$ & Recessive & Infancy & Impaired ? & Hyperphagia \\
\hline$o b R$ & Recessive & Infancy & Impaired & $\begin{array}{l}\text { Hyperphagia, pituitary } \\
\text { dysfunction }\end{array}$ \\
\hline POMC & Recessive & Infancy & Impaired? & $\begin{array}{l}\text { Hyperphagia, adrenal } \\
\text { insufficiency, red } \\
\text { hair pigmentation }\end{array}$ \\
\hline PC1 & Recessive & Infancy & Normal? & $\begin{array}{l}\text { Hyperphagia, } \\
\text { increased pro- } \\
\text { insulin levels, } \\
\text { decreased insulin } \\
\text { levels, } \\
\text { amenorrhoea }\end{array}$ \\
\hline MC4-R & Dominant & Infancy & Normal & Hyperphagia \\
\hline PPAR $\gamma$ & Dominant ? & $?$ & Normal & $\begin{array}{l}\text { Type-Il diabetes } \\
\text { mellitus? }\end{array}$ \\
\hline
\end{tabular}

POMC, pro-opiomelanocortin; PC1, prohormone convertase 1; MC4-R, melanocortin-4 receptor; PPAR $\gamma$, peroxisome-proliferator-activated receptor $\gamma$ 


\section{Adipose tissue cellularity during childhood and adolescence}

On the basis of their results derived from investigations of adipose tissue cellularity, several authors (for summary, see Brook, 1976; Knittle, 1976; Hauner et al. 1989b) were able to identify two sensitive periods for adipose tissue development during childhood: one during the first year of life; the second just before puberty. During the first year of life the increase in body fat content is mainly due to an increase in adipocyte volume. Further growth of adipose tissue, especially in the second filling period, is suggested to be mainly due to an increase in fat cell number without significant changes in fat cell volume (Knittle, 1976). According to these studies the mean fat cell volume does not increase between the second year of life and adulthood. When determining the activity of thymidine kinase in the stromal-vascular fraction of adipose tissue, two periods of high thymidine kinase activity were observed: in the first year of life; in the period just before puberty. The activity of this enzyme is a measure of the proliferation activity in this cell fraction in which pre-adipocytes are also present (Baum et al. 1985). This observation again supports the existence of two sensitive periods. According to these findings, during these periods an increase in the number of undifferentiated adipocytes occurs.

\section{Proliferation and differentiation of pre-adipocytes during childhood and adolescence}

To our knowledge, there is only one study in which proliferation and differentiation of pre-adipocytes derived from adipose tissue from children at different ages has been investigated (Hauner et al. 1989b). The results of this study showed age-dependent differences in proliferation activity and differentiation capacity of these cells cultured under serum-containing conditions. In accordance with the cyclic development of fat-free body mass and body fat mass during growth, it was shown that in the first year of life and in a period just before puberty these cells showed a maximum in their proliferation capacity as well as in their differentiation capacity. These data support the concept that the development of adipose tissue during childhood occurs mainly through the formation of new fat cells during sensitive periods. These periods might also be sensitive periods for the development of obesity. Several other lines of evidence also obtained from clinical follow-up data have recognized the same critical periods in childhood for the aquisition of obesity (Dietz, 1994; Rolland-Cachera et al. 1984).

Another interesting finding in this study was the observation that in adipose tissue of children compared with that of adults a much higher percentage of small fat cells with a diameter below $25 \mu \mathrm{m}$ can be found. This observation indicates that during childhood there is a higher extent of formation of new fat cells which subsequently increase their volume. Taken together the data from these and more recent studies using serum-free culture conditions show that the formation of new fat cells depends on age and occurs to a high degree during childhood (Hauner et al. 1989a; Wabitsch et al. 1996).

\section{Adipose tissue cellularity during changes in adipose tissue mass}

At the cellular level, changes in adipose tissue depot size result from changes in adipocyte volume and adipocyte number. The volume of an adipocyte represents the balance between lipolysis and lipogenesis at the level of a specific cell. Changes in adipocyte number are the result of either a multiplication of pre-adipocytes and their subsequent differentiation into adipocytes, resulting in an increase in fat mass, or de-differentiation or apoptosis of existing adipocytes, leading to a loss of adipose tissue mass. Several factors are involved in the regulation of both adipocyte volume and number, which also seem to be to a considerable extent genetically determined. The physiological regulation of adipocyte volume has been summarized elsewhere (Hauner, 1992). The regulation of pre-adipocyte differentiation and that of fat cell number by inhibition of differentiation, de-differentiation and apoptosis will now be summarized.

\section{Regulation of pre-adipocyte differentiation in man}

An adequate in vitro model for studying human adipocyte differentiation and metabolism has been described (Hauner et al. 1989b). In the undifferentiated stage these preadipocytes are not distinguishable macroscopically from fibroblasts. However, during adipose differentiation the cells change their morphology. They become spherical and their cytoplasm is slowly filled with multiple lipid droplets which increase in size. These morphological changes result from various biochemical processes during differentiation, until eventually the in vitro differentiated pre-adipocytes possess all the biochemical characteristics of mature fat cells.

Clinical observations demonstrate an important role of glucocorticoids, growth hormone, insulin and thyroid hormones in the control of adipose tissue cellularity (Ailhaud \& Hauner, 1997). In addition, in vitro data have shown that these hormones are important regulators of human adipocyte differentiation (Hauner et al. 1989a; Wabitsch et al. 1996). In our in vitro studies on human preadipocyte differentiation we showed that under serum-free culture conditions, physiological concentrations of insulin, triiodothyronine and cortisol are sufficient to stimulate adipose differentiation.

Furthermore, IGF-I is an important regulator of preadipocyte proliferation, differentiation and possibly also of the metabolism of adipocytes (Wabitsch et al. 1995). Since IGF-I and IGF-binding protein concentrations in the circulation are influenced by protein intake, it is reasonable to assume that the action of IGF-I could be an important link in the nutrition-dependent regulation of adipose tissue growth and metabolism. In this context it should be mentioned that in a follow-up study of nutrition and growth it was demonstrated that a high-protein diet early in life may increase the risk of obesity later in life (Rolland-Cachera et al. 1995). Since protein intakes of formula-fed infants are higher than those of breast-fed infants (Heinig et al. 1993), it can be hypothesized that this factor could partly explain the demonstrated dose-response effect of duration of breast- 
feeding on the prevalence of obesity in children at the age of 5 or 6 years (von Kries et al. 1999).

The phenotypical and functional changes which occur during the differentiation of a pre-adipocyte into an adipocyte are the result of molecular changes related to changes in the pattern of gene expression. The differentiation process is characterized by an increase in the expression of adipocyte-specific genes (e.g. lipoprotein lipase, glucose-6-phosphate dehydrogenase, glucose transporter 4 leptin, etc.) and the decrease in the expression of genes that are predominant in pre-adipocytes (e.g. pre-adipocyte factor-1). Changes in gene expression are regulated by transcription factors. In the last few years such 'key regulators' of adipocyte gene transcription have been described. It is now known that a combination of factors from the CCAAT-enhancer binding protein family and the PPAR family will positively activate adipocyte gene transcription. PPAR $\gamma 2$ directly stimulates the adipose differentiation process. If PPAR $\gamma 2$ is phosphorylated at the site of a single amino acid residue its activity and its ability to promote adipose differentiation is markedly reduced. The regulation of this phosphorylation seems to be a critical event in the control of adipose tissue growth (Hu et al. 1996; Ristow et al. 1998)

PPAR isoforms have natural ligands such as fatty acids, prostaglandins, or leukotrienes and related metabolites. Further knowledge of the role of such natural ligands in activating PPAR, and thus affecting the transcription of adipogenic genes will provide a better understanding of the link between the fatty acid composition of food and the formation of new fat cells (Ailhaud \& Hauner, 1997).

\section{Negative regulators of adipocyte number in man}

In human serum there are a number of circulating factors which are able to inhibit differentiation of pre-adipocytes, or which may even have the capacity to induce the de-differentiation or apoptosis of existing adipocytes (Prins \& O'Rahilly, 1997). In a study investigating the effect of human serum on differentiation of pre-adipocytes it was shown that the adipogenic activity of sera from obese children was reduced significantly $(P<0 \cdot 01)$ after they had lost $10 \%$ of their body weight (Hauner et al. 1989c). At the same time the anti-adipogenic activity increased.

Some of the factors recently identified as inhibiting differentiation of human pre-adipocytes include transforming growth factor $\beta$, tumour necrosis factor $\alpha$, epidermal growth factor and platelet-derived growth factor (Petruschke et al. 1994; Hauner et al. 1995).

A new field of research is the study of adipocyte apoptosis. In brown adipose tissue apoptosis plays an important role in controlling the number of heat-producing and energy-consuming cells, and in the postnatal decrease of brown adipose tissue size. However, the importance of apoptosis in the regulation of adipocyte number in white adipose tissue has still to be clarified.

In human adipose tissue apoptosis of fat cells has been shown to occur in patients with malignancies (Prins et al. 1994). In vitro studies using cultures of human preadipocytes or adipose tissue explant cultures identified tumour necrosis factor $\alpha$ as one factor capable of inducing apoptosis in human pre-adipocytes and adipocytes (Prins et al. 1997). Serum deprivation of cultured human preadipocytes also induces apoptosis in some of the cells, suggesting that specific serum factors are required to protect pre-adipocytes from entering into apoptosis (Niesler et al. 1998). It remains to be clarified in future studies whether apoptosis of pre-adipocytes and adipocytes in human white adipose tissue is a physiologically-relevant mechanism involved in the control of adipocyte number.

\section{References}

Ailhaud G \& Hauner H (1997) Development of white adipose tissue. In Handbook of Obesity, pp. 359-378 [GA Bray, C Bouchard and WPT James, editors]. New York: Marcel Dekker Inc.

Baum D, Beck RQ, Hammer LD, Brasel JA \& Greenwood MRC (1985) Adipose tissue thymidin kinase activity in man. Pediatric Research 20, 118-121.

Brook CGD (1976) Cellular growth: adipose tissue. In Human Growth, vol. 2, pp. 21-33 [F Falkner and JM Tanner, editors]. New York: Plenum Press.

Clement K, Vaisse C, Lahlou N, Cabrol S, Pelloux V, Cassuto D, Gourmelen M, Dina C, Chambaz J, Lacorte JM, Basdevant A, Bougneres P, Lebouc Y, Froguel P \& Guy-Grand B (1998) A mutation in the human leptin receptor gene causes obesity and pituitary dysfunction. Nature 392, 398-401.

Dietz WH (1994) Critical periods in childhood for the development of obesity. American Journal of Clinical Nutrition 59, 955-959.

Dugdale AE (1975) Pattern of fat and lean tissue deposition in children. Nature 256, 725-726.

Friedman JM \& Halaas JL (1998) Leptin and the regulation of body weight in mammals. Nature 395, 763-770.

Hauner H (1992) Physiology of the fat cells, with emphasis on the role of growth hormone. Acta Paediatrica Suppl. 383, 47-51.

Hauner H, Entenmann G, Wabitsch M, Gaillard D, Ailhaud G, Negrel R \& Pfeiffer EF (1989a) Promoting effect of glucocorticoids on the differentiation of human adipocyte precursor cells cultured in a chemically defined medium. Journal of Clinical Investigation 84, 1663-1670.

Hauner H, Röhrig K \& Petruschke T (1995) Effects of epidermal growth factor (EGF), platelet-derived growth factor (PDGF) and fibroblast growth factor (FGF) on human adipocyte development and function. European Journal of Clinical Investigation 25, 90-96.

Hauner H, Wabitsch M \& Pfeiffer EF (1989b) Proliferation and differentiation of adipocyte precursor cells from children at different ages. In Obesity in Europe 1988, pp. 195-200 [P Björntorp, editor]. London: John Libbey.

Hauner H, Wabitsch M, Zwiauer K, Widhalm K \& Pfeiffer EF (1989c) Adipogenic activity in sera from obese children before and after weight reduction. American Journal of Clinical Nutrition 50, 63-67.

Heinig MJ, Nommsen LA, Peerson JM, Lonnerdal B \& Dewey KG (1993) Energy and protein intakes of breast-fed and formula-fed infants during the first year of life and their association with growth velocity: the DARLING study. American Journal of Clinical Nutrition 58, 152-161.

Hu E, Kim JB, Sarraf P \& Spiegelman BM (1996) Inhibition of adipogenesis through MAP kinase-mediated phosphorylation of PPARgamma. Science 274, 2100-2103.

Jackson RS, Creemers JWM, Ohagi S, Raffin-Sanson ML, Sanders L, Montague CT, Hutton JC \& O'Rahilly S (1997) Obesity and impaired prohormone processing associated with mutations in the prohormone convertase 1 gene. Nature Genetics 16, 303-306. 
Knittle J (1976) Adipose tissue development in man. In Human Growth, vol. 2, pp. 295-315 [F Falkner and JM Tanner, editors]. New York: Plenum Press.

Krude H, Biebermann H, Luck W, Horn R, Brabant G \& Gruters A (1998) Severe early-onset obesity, adrenal insufficiency and red hair pigmentation caused by POMC mutations in human. Nature Genetics 19, 155-157.

Levine AL, Eberhardt NL \& Jensen MD (1999) Role of nonexercise activity thermogenesis in resistance to fat gain in humans. Science 283, 212-214.

Montague CT, Farooqi S, Whitehead JP, Soos MA, Rau H, Wareham NJ, Sewter CP, Digby JE, Mohammed SN, Hurst JA, Cheetham CH, Earley AR, Barnett AH, Prins JB \& O'Rahilly S (1997) Congenital leptin deficiency is associated with severe early-onset obesity in humans. Nature 387, 903-908.

Niesler CU, Siddle K \& Prins JB (1998) Human preadipocytes display a depot-specific susceptibility to apoptosis. Diabetes $\mathbf{4 7}$, 1365-1368.

Petruschke T, Röhrig K \& Hauner H (1994) Transforming growth factor beta (TGF- $\beta$ ) inhibits the differentiation of human adipocyte precursor cells in primary culture. International Journal of Obesity 18, 532-536.

Prins JB, Walker NI, Winterford CM \& Cameron DP (1994) Human adipocyte apoptosis occurs in malignancy. Biochemical and Biophysical Research Communications 205, 625-630.

Prins JB \& O'Rahilly S (1997) Regulation of adipose cell number in man. Clinical Science 92, 3-11.

Prins JB, Niesler CU, Winterford CM, Bright NA, Siddle K, O'Rahilly S, Walker NI \& Cameron DP (1997) Tumor necrosis factor-alpha induces apoptosis of human adipose cells. Diabetes 46, 1939-1944.

Ristow M, Müller-Wieland D, Pfeiffer A, Krone W \& Kahn R (1998) Obesity associated with a mutation in a genetic regulator of adipocyte differentiation. New England Journal of Medicine 339, 953-959.
Rolland-Cachera MF, Deheeger M, Akrout M \& Bellisle F (1995) Influence of macronutrients on adiposity development: a follow up study of nutrition and growth from 10 months to 8 years of age. International Journal of Obesity 19, 573-578.

Rolland-Cachera MF, Deheeger M, Bellisle F, Sempe M, GuilloudBataille M \& Patois E (1984) Adiposity rebound in children: a simple indicator for predicting obesity. American Journal of Clinical Nutrition 39, 129-135.

Rosenbaum M \& Leibel RL (1998) The physiology of body weight regulation: relevance to the etiology of obesity in children. Pediatrics 101, 525-539.

Strobel A, Camoin TIL, Ozata M \& Strossberg AD (1998) A leptin missense mutation associated with hypogonadism and morbid obesity. Nature Genetics 18, 213-215.

Troiano RP \& Flegal AM (1998) Overweight children and adolescents: description, epidemiology, and demographics. Pediatrics 101, 497-504.

Vaisse C, Clement K, Guy-Grand B \& Froguel P (1998) A frameshift mutation in human MC4R is associated with a dominant form of obesity. Nature Genetics 20, 113-114.

von Kries R, Koletzko B, Sauerwald T, von Mutius E, Barnert D, Grunert V \& von Voss H (1999) Breast feeding and obesity: cross sectional study. British Medical Journal 319 147-150.

Wabitsch M, Hauner H, Heinze E \& Teller W (1995) The role of GH/IGF's in adipocyte differentiation. Metabolism 44, Suppl., 45-49.

Wabitsch M, Braun S, Hauner H, Heinze E, Ilondo MM, Shymko R, De Meyts P \& Teller WM (1996) Mitogenic and antiadipogenic properties of human growth hormone in human adipocyte precursor cells in primary culture. Pediatric Research 40, 450-456.

Yeo GS, Faroogi IS, Aminian S, Halsall DJ, Stanhope RG \& O'Rahilly S (1998) A frameshift mutation in MC4R associated with dominantly inherited human obesity. Nature Genetics 20, $111-112$ 